\title{
Karakteristik Surel Bisnis Berbahasa Korea
}

\section{Characteristics of Korean Business E-mails}

\author{
Alfiana Amrin Rosyadi \\ Universitas Gadjah Mada \\ alfianaraharjo@gmail.com
}

\begin{abstract}
With the increasing number of Korean companies that are having business operation in Indonesia, a balance can be attained by providing sufficient workforces who are fluent in business in Korean. One of the required skills is the ability to write a business email. Despite required for researches and books about Korean business, especially on the topic of Korean business emails in Indonesia has so far not been considered an important topic in Korean language. Therefore, this research aims to discover and show the characteristics of business emails in Korean by dividing them into structural, language, and cultural categories. To obtain the result, 30 emails were collected from a Korean language teaching institution and a Korean manufacturing company. Based on the results, it shows that Korean business email has characteristics based on the three categories of business emails analyzed. There are also writing differences between language institutes and manufacturing companies regarding to their different business fields. These differences must be understood by Korean language learners who want to work in Korean companies in Indonesia or Korea to avoid misunderstandings.
\end{abstract}

Keywords: business email, characteristic, Korean language

\section{INTISARI}

Banyaknya perusahaan Korea yang ada di Indonesia seharusnya diimbangi dengan tenaga kerja yang memiliki kemampuan bahasa Korea bisnis yang memadai. Menulis surel bisnis dalam Bahasa Korea merupakan salah satu bentuk kemampuan berbahasa Korea bisnis. Walaupun diperlukan, penelitian atau buku-buku tentang bahasa Korea bisnis khususnya tentang surel bisnis di Indonesia sampai saat ini belum mendapatkan perhatian. Oleh karena itu, penelitian ini bertujuan untuk mengetahui dan menyajikan karakteristik surel bisnis berbahasa Korea, baik karakteristik struktural, bahasa maupun budaya. Untuk mencari jawaban pertanyaan tersebut peneliti telah mengumpulkan 30 buah surel bisnis berbahasa Korea dari lembaga pendidikan Korea dan juga surel bisnis dari perusahaan manufaktur Korea. Dari surel-surel bisnis tersebut, dapat disimpulkan bahwa surel bisnis berbahasa Korea memiliki karakteristik berdasarkan dari tiga kategori yang dianalisis. Terdapat pula perbedaan antara penulisan surel bisnis di lembaga pendidikan dan di perusahaan manufaktur karena bidang usaha yang berbeda. Hal ini harus dipahami oleh pembelajar bahasa Korea yang ingin bekerja di perusahaan atau badan usaha milik Korea baik di Indonesia maupun di Korea agar tidak terjadi kesalahpahaman.

Kata kunci: bahasa Korea, karakteristik, surel bisnis

Panduan sitasi:

Rosyadi, A. A. (2020). Karakteristik Surel Bisnis Berbahasa Korea. JLA (Jurnal Lingua Applicata), 4(1), Hal. 13-26 


\section{PENDAHULUAN}

Kemampuan menulis surel (kependekan dari 'surat elektronik' atau yang biasa disebut e-mail) adalah salah satu kemampuan dasar yang dibutuhkan oleh pekerja di lingkungan kantor. Berbagai komunikasi dilakukan dengan cara mengirim surel, baik antar atasan dan bawahan atau bahkan perusahaan dengan pembeli. Ini diperkuat dengan hasil survei tentang Adobe Email Usage Study oleh Adobe (2019) yang mengambil data dari 1002 orang dewasa di Amerika Serikat. Hasil survei ini menunjukkan bahwa $80 \%$ masyarakat lebih sering mengecek surel bisnis daripada surel personal.

Surel bisnis memiliki karakteristik yang berbeda dengan surel personal. Surel bisnis tidak hanya membawa nama pribadi penulis tetapi juga nama perusahaan. Karena penulis membawa nama perusahaan, struktur dan gaya bahasa yang digunakan dalam surel bisnis berbeda dari surel personal. Etika dalam mengirim surel juga harus diperhatikan. Penyebutan nama dan juga jabatan bisa menjadi hal yang penting dalam surel bisnis.

Berbagai karakteristik yang dimiliki surel bisnis membuat penulis surel seringkali mengalami kesulitan. Apalagi jika surel yang ditulis bukanlah surel berbahasa Indonesia. Surel dalam bahasa asing tentunya memiliki ciri khusus yang berbeda dengan surel bisnis dalam bahasa Indonesia. Ini terjadi karena pola komunikasi dan juga bahasa yang digunakan berbeda.
Salah satu surel berbahasa asing yang digunakan dalam dunia kerja di Indonesia adalah surel dalam bahasa Korea. Surel bisnis berbahasa Korea banyak digunakan di dalam lingkungan perusahaanperusahaan Korea, terutama oleh para penerjemah yang melakukan komunikasi langsung dengan atasan-atasan orang Korea. Oleh karena itu, bagi pembelajar bahasa Korea, kemampuan menulis surel bisnis menjadi sebuah nilai tambah.

Surel bisnis dalam bahasa Korea memiliki persamaan dan perbedaan dengan surel dalam bahasa Indonesia. Dari segi bahasa, bahasa Korea memiliki berbagai tingkat tutur, sedangkan bahasa Indonesia tidak. Kesopanan harus diperhatikan ketika menulis surel berbahasa Korea. Selain itu, ekspresi penghalusan kalimat (downgrader) dalam bahasa Korea juga berbeda dengan bahasa Indonesia. Perbedaan dari segi bahasa maupun dari segi struktural bisa jadi menyulitkan pembelajar bahasa Korea ketika ingin menulis surel.

Meskipun penelitian yang berhubungan dengan surel bisnis dalam bahasa Korea sangat diperlukan, berdasarkan penelusuran yang telah dilakukan, hanya ditemukan hasil penelitian terkait tema ini dalam bahasa Korea dan belum ditemukan penelitian yang membahas perbedaan surel bisnis Korea dalam bahasa Indonesia. Lee (2015) menulis penelitian untuk pengembangan materi pengajaran bahasa Korea bisnis melalui analisis wacana dalam surel bisnis bahasa Korea. Sementara itu, Kim (2018) 
mengkaji tentang teks surel bisnis untuk pengajaran bahasa Korea, dan Linyan (2020) meneliti strategi permintaan dalam surel bisnis.

Walau terdapat perbedaan antara surel berbahasa Korea dan surel berbahasa Indonesia, surel bisnis tetap memiliki kesamaan karakteristik yaitu formalitas, legalitas, privasi, dan pesan yang lugas (Smith, 2002; Kallos, 2008). Formalitas di sini bisa ditunjukkan dalam gaya bahasa yang digunakan. Bahasa yang digunakan dalam surel bisnis bukanlah bahasa pergaulan sehari-hari.

Formalitas juga ditunjukkan dari nama alamat surel pengirim (Smith, 2002; Kallos, 2008). Surel yang tidak menggunakan nama terang atau nama perusahaan akan membuat penerima surel merasa tidak nyaman. Formalitas juga ditunjukkan dari penulisan judul surel. Judul surel bisnis menunjukkan tujuan dari pengiriman surel. Berbeda dari judul di surel pribadi yang bisa ditulis hanya dengan sapaan salam.

Legalitas dalam surel bisnis diperlukan untuk menjamin kepercayaan kedua belah pihak (Smith, 2002; Kallos, 2008). Untuk menunjukkan legalitas dalam surel bisnis, pengirim surel menggunakan fitur tanda tangan di surel. Di fitur tersebut pengirim dapat menambahkan kartu nama dirinya atau perusahaan, lengkap dengan logonya. Selain itu, pengirim surel harus menjamin file yang dikirimkan ke penerima adalah file yang hak ciptanya dimiliki sendiri atau tidak melanggar hak cipta orang lain.
Privasi juga diperhatikan dalam penulisan surel bisnis (Smith, 2002; Kallos, 2008). Surel bisnis biasanya menyertakan penerima surel lainnya. Surel bisnis tidak mewakili individu, jadi bagian perusahaan yang perlu informasi di surel tersebut akan disertakan. Selain itu, pengirim bisa mengatur surel yang dikirimkannya menjadi surel konfidensial. Surel konfidensial adalah surat yang isinya bersifat rahasia dan hanya untuk kalangan tertentu. Jika penerima surel bukanlah penerima surel yang seharusnya, ia wajib memberitahukan ke pengirim. Saat ini salah satu layanan surel terbesar, Google, telah membuat fitur surel berjangka. Surel ini hanya bisa dilihat dalam jangka waktu yang ditentukan pengirim. Selain itu, ada fitur kata sandi SMS untuk keamanan surel.

Salah satu karakteristik surel bisnis adalah penggunaan bahasa yang lugas dan tidak bertele-tele. Surel bisnis tidak menggunakan bahasa kiasan dan ditulis dengan kalimat yang singkat, padat dan jelas. Ini ditujukan agar penerima dapat langsung memahami dengan mudah tujuan pengiriman surel bisnis tersebut.

Surel bisnis dalam bahasa Korea memiliki karakteristik tersendiri. Kim (2012) membagi karakteristik surel Korea ke dalam karakteristik struktural, bahasa dan strategi. Sementara, Xin (2018) menambahkan pembagian karakteristik budaya. Penelitian ini akan memfokuskan penelitian pada karakteristik struktural, bahasa dan budaya. Karakteristik struktural berkaitan dengan susunan penulisan surel. Susunan penulisan surel antara lain adalah 
judul, salam pembuka, bagian pembuka, bagian penutup, salam penutup dan bagian tanda tangan. Karakteristik bahasa terkait dengan bahasa yang digunakan dalam surel. Kosa kata dan ekspresi khusus termasuk kategori ini. Karakteristik budaya mencerminkan kekhususan yang dimiliki surel bisnis Korea.

Dari paparan di atas, penelitian ini penting dilakukan karena belum ada penelitian surel bisnis berbahasa Korea di Indonesia. Hasil penelitian ini dapat membantu para pembelajar bahasa Korea yang sedang mempersiapkan diri untuk memasuki dunia kerja, juga bagi para tenaga kerja penutur bahasa Korea yang telah berkiprah di dunia industri.

\section{METODE PENELITIAN}

Penelitian ini bertujuan untuk menganalisis karakteristik struktural, bahasa dan budaya dalam penulisan surel bisnis berbahasa Korea. Karakteristik surel berbahasa Korea ini perlu dibagi menjadi beberapa kategori agar bisa mendapatkan gambaran surel bisnis berbahasa Korea secara utuh.

Metode yang digunakan adalah metode penelitian kualitatif. Penelitian kualitatif dipilih agar penelitian ini dapat menyajikan secara jelas karakteristik surel dalam bahasa Korea yang benar-benar ditulis oleh penutur asli. Surel bisnis berbahasa Korea dikumpulkan dari surel bisnis selama peneliti menjadi penerjemah di perusahaan manufaktur Korea (20142015) dan surel bisnis lain yang didapat penulis selama menjadi guru bahasa di lembaga pengajaran bahasa Korea (20192020) sebanyak 30 surel. Alasan kedua jenis surel bisnis diambil sebagai sampel karena keduanya memiliki perbedaan penggunaan bahasa Korea di dalam surel. Surel bisnis yang didapat kemudian dianalisis mengunakan kategori-kategori seperti pada tabel 1. Hasil analisis disajikan dalam tabel sesuai kategori-kategori tersebut, kemudian dijelaskan secara deskriptif. Hal ini dilakukan agar hasil analisis tersajikan dengan jelas dan tidak ambigu.

Tabel 1. Tabel Analisis

\begin{tabular}{|c|c|}
\hline Karakteristik & Komponen \\
\hline Struktural & $\begin{array}{l}\text { Judul; Salam pembuka; Bagian } \\
\text { pembuka; Bagian penutup; } \\
\text { Salam penutup dan bagian tanda } \\
\text { tangan }\end{array}$ \\
\hline Bahasa & $\begin{array}{l}\text { Kosa kata khusus; Ekspresi } \\
\text { khusus }\end{array}$ \\
\hline Budaya & $\begin{array}{l}\text { Unsur-unsur budaya Korea } \\
\text { dalam surel bisnis }\end{array}$ \\
\hline
\end{tabular}

Sumber: data penelitian

Hasil dari analisis disajikan dalam tiga kategori utama yaitu berdasarkan karakteristik struktural, bahasa dan budaya. Karakteristik struktural dibagi lagi dalam lima bagian dari struktur surel yaitu judul, salam pembuka, bagian pembuka, bagian penutup, serta salam penutup dan bagian tanda tangan. Inti dari surel tidak diikutsertakan karena setiap surel memiliki isi yang berbeda. Karakteristik bahasa berkaitan dengan kosakata dan ekspresi khusus yang muncul dalam surel. Sedangkan karakteristik budaya berkaitan dengan kekhususan budaya Korea yang tercermin dalam penulisan surel. 


\section{HASIL DAN PEMBAHASAN}

\section{1) Karakteristik Struktural dalam Surel}

\section{Bisnis Berbahasa Korea}

Pada bagian ini, akan dijelaskan tentang karakteristik dari struktur surel bisnis berbahasa Korea. Pembahasan meliputi judul, salam pembuka, bagian pembuka, bagian penutup, serta salam dan bagian tanda tangan.

Berdasarkan hasil analisis data penelitian, dapat diketahui bahwa judul dalam surel bisnis biasanya tidak dimulai dengan “insa"/인사 ('salam') seperti "annyeonghaseyo" (안녕하세요) atau "annyeonghasimnikka" (안녕하십니까). Judul pada surel bisnis lugas dan banyak menggunakan kata benda. Hal tersebut dapat dilihat dalam tabel 2 .

Tabel 2. Judul dalam Surel Bisnis

\begin{tabular}{lc}
\hline \multicolumn{1}{c}{ Jenis Judul } & Jumlah \\
\hline Pemberitahuan & 10 \\
Lain-lain & 6 \\
Permintaan & 5 \\
Kata benda bidang khusus & 5 \\
Surel terusan & 2 \\
Survei & 2 \\
\hline
\end{tabular}

Sumber data: data penelitian

Judul surel yang muncul paling banyak adalah berupa pemberitahuan (33\%). Pemberitahuan dalam bahasa Korea bisa ditulis dengan "annae" (안내), "gongji" (공지) dan "allim" (알림). Misalnya surel yang dikirimkan oleh kantor pusat lembaga pengajaran bahasa Korea di Korea kepada setiap cabang lembaga pengajaran bahasa Korea di Indonesia. Surel ini berisi pemberitahuan untuk menyaring siswa- siswa unggul di lembaga pengajaran tersebut. Judul yang digunakan pada surel tersebut adalah "mojip annae" (모집 안내). Mojip di sini berarti 'perekrutan'.

Setelah pemberitahuan, judul yang paling banyak keluar adalah permintaan atau yocheong (요청) (16\%), kata benda bidang khusus (16\%) dan lain-lain (20\%). Surel permintaan cukup banyak diterima karena kantor pusat lembaga pengajaran tersebut membutuhkan dokumen yang harus diisi dan kemudian dikumpulkan. Untuk perusahaan di bidang manufaktur, judul surel terlihat sedikit berbeda. Surel dituliskan dengan menyebutkan kata benda khusus seperti banpum/반품 ('barang retur') atau masalah gumaeodeo munje /구매오더 문제 ('purchase order'). Sementara itu, surel yang masuk dalam kategori lain-lain memiliki judul yang berbeda-beda. Contohnya, unyeongwonkke mojip/ 운영원께 모집 ('kepada pengelola') dan halil/할일 ('hal yang akan dilakukan').

Selanjutnya, surel yang paling sedikit diterima adalah surel terusan dan surel survei. Surel terusan dalam bahasa Korea ditulis "jeondal" (전달) atau juga surel berbagi yang disebut gongyu (공유). Dua surel ini dijadikan satu kategori karena berisi penerusan informasi. Survei disebut josa (조사) dalam bahasa Korea dan biasanya dikirimkan jika kantor pusat dari lembaga pengajaran tersebut sedang mengembangkan suatu program baru.

Bagian salam pembuka dalam surel berbahasa Korea terdiri dari salam pembuka seperti "annyeonghaseyo" atau "annyeonghasimnikka". Dalam surel bisnis, salam 
dengan bahasa pergaulan seperti "annyeong" (안녕) tidak digunakan. Sapaan untuk panggilan dalam bahasa Korea disebut hoching (호칭). Pada surel bisnis, sapaan termasuk dalam salam pembuka dan digunakan oleh pengirim sesuai dengan jabatan penerima surel seperti yang dapat dilihat pada tabel 3.

Tabel 3. Salam Pembuka dalam Surel Bisnis

\begin{tabular}{lc}
\hline \multicolumn{1}{c}{$\begin{array}{c}\text { Jenis salam pembuka yang } \\
\text { digunakan }\end{array}$} & Jumlah \\
\hline Annyeonghaseyo & 7 \\
annyeonghaseyo+nama pengirim & 5 \\
annyeonghaseyo+jabatan +nama & 5 \\
pengirim & \\
jabatan penerima & 3 \\
nama penerima & 5 \\
annyeonghaseyo+nama perusahaan & 3 \\
Annyeonghasimnikka & 1 \\
tidak ada salam pembuka & 1 \\
\hline
\end{tabular}

Sumber data: data penelitian

Aturan sapaan dalam dunia bisnis menurut Myeong (2019), jabatan ditambahkan nim (님) sebagai bentuk sapaan. Misalnya untuk menyapa kepala departemen (bujang/부장) ditambah nim sehingga disebut bujangnim (부장님). Di bawah bujangnim, ada chajangnim/ 차장님 ('manajer senior'), gwajangnim/ 과장님 ('manajer'), dan daerinim/대리님 ('asisten manajer'). Setiap perusahaan memiliki struktur jabatan yang berbeda. Ada perusahaan yang memiliki jabatan bumunjangnim/부문장님 ('kepala proyek'), timjangnim/팀장님 ('kepala tim'), dan juga menggunakan campuran bahasa Inggris seperti maenijeonim/매니저님 ('manajer'). Penggunaan sapaan seperti ini berbeda dengan surel di Indonesia yang lebih banyak menggunakan kata sapaan "Bapak" dan "Ibu" (Damar, 2010). Fungsi sapaan "Bapak" dan "Ibu" ini bukan untuk menuakan, tetapi sebagai bentuk penghormatan.

Dari tabel 3 dapat diketahui bahwa salam pembuka surel bisnis dalam bahasa Korea lebih banyak didominasi oleh salam annyeonghaseyo daripada salam pembuka lainnya. Di perusahaan manufaktur, annyeonghaseyo digunakan karena pengirim dan penerima saling mengetahui jabatan dan nama masing-masing. Setelah annyeonghaseyo, dari data penelitian, terdapat empat variasi salam pembuka lainnya yang muncul dengan jumlah yang sama (masing-masing berjumlah 5). Perbedaan antara keempatnya bisa dilihat dalam contoh a-d berikut:

a. 안녕하세요. 홍일동입니다.

Anyeonghaseyo. Hong Ildong-imnida. 'Selamat pagi/siang/petang. Saya Hong Ildong.'

b. 안녕하세요. 문화사업부 홍일동입니다 Anyeonghaseyo. Munhwa Saeopbu Hong Ildongimnida

'Selamat pagi/siang/petang. Saya Hong Ildong dari departemen Kebudayaan.'

c. 선생님

Seonsaengnim.

'Guru.'

d. 홍일동.

Hong Ildong.

'Hong Ildong.' 
Untuk salam pembuka nomer a hanya dituliskan salam dan nama pengirim. Surel ini dikirimkan oleh manajer Korea dari kantor cabang untuk para pengajar. Penerima dan pengirim masing-masing mengetahui jabatan masing-masing sehingga hanya nama yang ditulis. Sementara untuk salam pembuka nomer $b$, pengirim menuliskan salam, namanya, dan jabatannya di tempat bekerja. Surel berisi salam pembuka seperti nomer b ini biasanya dikirimkan oleh manajer Korea dari bagian tertentu di kantor pusat kepada pengelola dan guru-guru di kantor cabang. Sapaan nomer $\mathrm{b}$ biasanya digunakan oleh pengirim yang tidak mengenal dekat penerima. Sedangkan untuk sapaan nomer c, digunakan oleh pengirim yang mengetahui jelas posisi penerima di lembaga pengajaran. Salam pembuka ini misalnya digunakan oleh kepala cabang saat mengirimkan surel kepada para pengajar di kantor cabang. Ini berbeda dengan salam pembuka yang digunakan dalam surel bisnis di perusahaan. Di perusahaan, jika seseorang belum memiliki jabatan, biasanya akan dipanggil nama. Jabatan interpreter tidak akan dipanggil tongyeoksanim (통역사님) di surel dan hanya ditulis nama.

Struktur surel setelah judul dan salam pembuka adalah bagian pembuka. Bagian pembuka di surel bisnis tidak selalu ada. Akan tetapi, ada beberapa pola yang muncul dalam bagian pembuka. Di perusahaan manufaktur, salam pembuka seringkali tidak ditulis. Hal ini karena biasanya pesan surel ditulis singkat sehingga langsung masuk ke inti pesan.
Tabel 4 menunjukkan bahwa "OO deurimnida" (OO 드립니다) menjadi bagian pembuka yang paling banyak muncul. Ekspresi ini memang paling banyak digunakan di surel karena memberi tahu kepada penerima surel tujuan dari pengiriman surel. Bentuk deurida (드리다) yang berarti 'memberi', merupakan bentuk sopan dari juda (주다) dan digunakan di surel-surel formal. Ini menujukkan bahwa dalam surel bisnis berbahasa Korea kesopanan juga diperhatikan.

Tabel 4. Bagian Pembuka dalam Surel Bisnis

\begin{tabular}{lc}
\hline \multicolumn{1}{c}{ Pembuka surel } & Jumlah \\
\hline Tidak ada bagian pembuka & 10 \\
OO 드립니다 & 7 \\
(OO deurimnida) & \\
'Saya/Kami kirimkan OO' & 5 \\
Lain-lain & 2 \\
OO 고 있습니다 & \\
(OO go isseumnida) & \\
'Kami sedang OO' & 2 \\
OO 주셔서 감사합니다 & \\
(OO jusyoseo gamsahamnida) & \\
'Terima kasih karena OO' & \\
OO 드리고자 합니다 & \\
(OO deurigoja hamnida) & \\
'Kami ingin OO' & \\
고생많으십니다 \\
(gosaengmaneusimnida) \\
'Kamu sudah bekerja keras' \\
\hline$\quad$ Sumber data: data penelitian
\end{tabular}

Bentuk lain dari bagian pembukaan biasanya berupa pemberitahuan seperti "OO go isseumnida" (OO 고 있습니다). Bentuk ini digunakan di surel bisnis untuk memberitahukan kepada penerima jika pengirim saat ini sedang menjalankan sebuah program atau proyek. Selain bentuk pemberitahuan, ada bentuk ucapan terima kasih, penyampaian maksud atau keinginan 
pengirim dan ucapan penghargaan kepada penerima. Bentuk yang tidak ada kesamaan dengan bentuk lainnya dikategorikan dalam lain-lain. Salah satu contohnya adalah "jaegongjiga wasseoyo" (재공지가 왔어요). Ungkapan ini memberitahukan adanya revisi atas pemberitahuan yang sebelumnya. Jaegongji (재공지) artinya adalah 'pengumuman ulang' dan wasseoyo (왔어요) artinya 'sudah datang'.

Jika bagian pembuka surel bisnis menunjukkan tujuan dari pengiriman surel, bagian penutup dari surel bisnis mengekspresikan permintaan kepada penerima. Tabel 5 menunjukkan bahwa struktur surel bisnis tidak selalu memiliki bagian penutup. Ini dikarenakan pengirim bisa langsung menutup surel dengan salam penutup.

Tabel 5. Bagian Penutup dalam Surel Bisnis

\begin{tabular}{lc}
\hline \multicolumn{1}{c}{ Penutup Surel } & Jumlah \\
\hline Tidak ada bagian penutup & 13 \\
Permintaaan & 7 \\
Pengharapan & 4 \\
$\begin{array}{l}\text { Doa untuk kesehatan/semangat/ } \\
\text { Kebahagiaan }\end{array}$ & 4 \\
Lain-lain & 2 \\
\hline
\end{tabular}

Sumber data: data penelitian

Ungkapan permintaan seperti "OO butakdeurimnida" (OO 부탁드립니다) atau "OO butakdeurigesseumnida" (OO 부탁드리겠습니다) banyak dipakai di surel berbisnis dalam bahasa Korea. butakdeurida (부탁드리다) adalah bentuk sopan dari butakada (부탁하다). Ungkapan permohonan memberikan beban kepada penerima. Karena itu, pengirim menggunakan bentuk sopan agar tidak terkesan seperti menyuruh. Akan tetapi, hal yang berbeda ditemukan di surel perusahaan manufaktur. Jika yang mengirim adalah atasan, bentuk "OO juda" (OO 주다) juga digunakan. Dalam kasus ini, bentuk sopan tidak digunakan.

Selain bentuk permohonan, bentuk pengharapan seperti "OO baramnida" (OO 바랍니다) juga banyak digunakan. Dalam bagian penutup, beberapa pengirim surel juga menggunakan ungkapan doa. Doa yang sering dituliskan adalah agar penerima surel tetap diberi kesehatan. Ada juga bentuk ungkapan lain yang digunakan, tetapi karena berbeda dari kategori sebelumnya, bentuk-bentuk tersebut dimasukkan dalam kategori 'lain-lain'. Contohnya ungkapan penutup "daeume joheun haengsaro yollakdeurigesseumnida" (다음에 좋은 행사로 연락드리겠습니다) yang berarti 'Saya akan menghubungi Anda kembali kalau nanti ada acara yang bagus'. Ungkapan ini memberikan harapan kepada penerima supaya kedua belah pihak dapat kembali bekerja sama di masa mendatang.

Tabel 6. Salam Penutup dalam Surel Bisnis

\begin{tabular}{lc}
\hline \multicolumn{1}{c}{ Salam Penutup yang digunakan } & Jumlah \\
\hline gamsahamnida (감사합니다) & 10 \\
gamsahamnida+nama+deurim (드림) & 9 \\
tanpa salam penutup & 6 \\
gamsahamnida+jabatan+deurim & 2 \\
gamsahamnida+jabatan+nama+deurim & 1 \\
gamsahamnida+nama & 1 \\
Gomapseumnida & 1 \\
\hline
\end{tabular}

Sumber data: data penelitian

Bagian terakhir dalam struktur surel bisnis yang dianalisis adalah salam penutup 
dan bagian tanda tangan. Bentuk yang paling banyak muncul adalah ucapan terima kasih. 'Terima kasih' dalam bahasa Korea dapat diungkapkan dengan ucapan "gamsahamnida" (감사합니다) atau "gomapseumnida" (고맙습니다). Tabel 6 menunjukkan bahwa bentuk gamsahamnida lebih banyak digunakan. Dalam Kamus Standar Bahasa Korea, bentuk gamsahamnida diambil dari kata gamsahada (감사하다) yang berarti gomapkke yeogida (고맙게 여기다). Dalam bahasa Indonesia dapat diartikan sebagai 'anggapan berterima kasih'. Sedangkan gomapseumnida berasal dari kata gomaptta (고맙다). Dalam Kamus Pelajaran Bahasa Korea-Indonesia, kata ini diartikan sebagai 'perasaan senang dan ingin membalas budi kepada orang lain yang telah melakukan kebaikan untuk kita'. Menurut website resmi Pusat Bahasa Nasional Korea, ada pendapat yang beranggapan bahwa kata gomaptta lebih sopan dari gamsahada yang diambil dari hanja (한자), sehingga kata gomaptta harus lebih banyak digunakan. Menurut Kamus Pelajaran Bahasa KoreaIndonesia, hanja adalah huruf asli Cina yang dibuat di Cina dan sampai saat ini pun masih digunakan di Korea.

Variasi bentuk gamsahamnida yang paling banyak ditemukan adalah gabungan antara gamsahamnida, nama pengirim, dan deurim (드림). Deurim adalah bentuk pembendaan dari kata kerja deurida (드리다) yang digabung dengan $\square$ (partikel m untuk membendakan kata kerja). Bentuk ini dapat diartikan bahwa surel tersebut diberikan oleh pengirim. Di bahasa Korea nama dituliskan terlebih dahulu sebelum deurim. Bentuk ini adalah bentuk sopan dari sseum (씀) yang berarti dituliskan oleh pengirim. Jika surel ini dikirimkan oleh atasan biasanya hanya ucapan terima kasih atau ucapan terima kasih ditambah nama dari pengirim. Surel bisnis di perusahaan manufaktur hampir semuanya tidak menggunakan salam penutup. Ini dikarenakan surel di perusahaan dikirimkan oleh atasan dan merupakan balasan cepat. Banyak surel perusahaan yang hanya berisi inti surel. Nama tidak dituliskan karena di bawah biasanya sudah ada kartu nama digital.

\section{2) Karakteristik Bahasa dalam Surel Bisnis Berbahasa Korea}

Tabel 7. Kosakata Khusus dalam Surel Bisnis

\begin{tabular}{cl}
\hline Kategori & \multicolumn{1}{c}{ Kosakata yang digunakan } \\
\hline Pemberitahuan & $\begin{array}{l}\text { 모집 } \\
\text { (gonggomun), 안내 (annae), 홍보 } \\
\text { (hongbo), 재공지 (jaegongji) }\end{array}$ \\
Tenaga kerja & 채용 (chaeyong), 교육 역량 강화 \\
& (gyoyuk yeongnyang ganghwa), \\
& 고용 수요 및 가능 여부 (goyong \\
& suyo mit ganeung yeobu), \\
& 인건비 지급 (ingeonbi jigeub). \\
& 작성 불필요 (jakseong \\
& bulpiryeo), 증빙 서류 (jeungbing \\
& seoryu). \\
& 빌링 문자 (billing munja), \\
& 반제되지 않은 경우 (banje dwoeji \\
& anheun gyeongu), 표준 원가 \\
Pabrik & (pyojun wonga), 자재 코드 재고 \\
& (jajae kodeu jaego), 반품 반입 \\
& 처리 (banpum banip cheori), \\
& 영업 오더 (yeongeop odeo), dan \\
& 주문 오더 (jumun odeo).
\end{tabular}

Sumber data: data penelitian 
Karakteristik bahasa dalam surel bisnis berbahasa Korea dibagi menjadi dua kategori. Dua kategori tersebut adalah kosakata khusus dan ekspresi khusus. Kosakata dan ekspresi khusus yang muncul di surel menyesuaikan isi pesan. Tabel 7 menunjukkan kosakata khusus yang ditemukan dalam data penelitian. Kosakata khusus yang muncul dapat dibagi menjadi empat jenis, yaitu kosakata khusus berkaitan dengan pemberitahuan, lowongan kerja, dokumen, dan pabrik.

Dalam surel pemberitahuan, kosakata khusus yang muncul antara lain mojip (모집), gonggomun (공고문), annae (안내), hongbo (홍보) dan jaegongji (재공지). Arti harfiah dari mojip adalah 'pengumpulan'. Akan tetapi, biasanya mojip digunakan untuk memberitahukan adanya pembukaan lowongan. Surel pemberitahuan lowongan pekerjaan biasanya menggabungkan antara mojip dan gonggomun yang berarti 'pengumuman'. Jika kedua kata tersebut digabungkan, dapat diartikan sebagai 'pengumuman pembukaan lowongan kerja'.

Hal-hal yang berkaitan tentang tenaga kerja juga banyak muncul dalam surel bisnis yang dianalisis. Chaeyong (채용) berarti 'membuka lapangan kerja', gyeoyuk yeongnyang ganghwa (교육 역량 강화) berarti 'penguatan kompetensi pendidikan', goyong suyo mit ganeung yeobu (고용 수요 및 가능 여부) berarti 'ada tidaknya permintaan dan peluang untuk membuka lapangan pekerjaan', dan ingeonbi jigeub (인건비 지급) yang berarti 'pembayaran biaya tenaga kerja'.
Kosakata khusus lain yang muncul dalam bisnis adalah kosakata yang berhubungan dengan dokumen. Dalam surel-surel bisnis yang bersifat permintaan, kosakata seperti jakseong bulpiryeo (작성 불필요) dan jeungbing seoryu (증빙 서류) banyak digunakan. Jakseong bulpiryeo artinya 'tidak perlu dibuat dokumen' dan jeungbing seoryu dapat diterjemahkan sebagai 'dokumen untuk pembuktian'. Di Korea, semua perusahaan atau badan usaha lain membutuhkan jeungbing seoryu ketika mereka membayar tenaga kerja. Karena itu, badan usaha akan meminta foto atau pindaian dari buku tabungan (tongjang sabon/통장 사본) dan juga data diri (iryeoksseo/이력서).

Kosakata khusus yang digunakan di dalam pabrik manufaktur dapat dikatakan memiliki ciri tersendiri. Kosakata yang muncul berhubungan dengan bahasa pabrik yang meliputi 'pembelian', 'produksi', 'pemasaran' dan juga 'pengembalian barang'. Kosakata yang muncul dalam surel antara lain billing munja (빌링 문자) yang berarti 'pesan tagihan pembayaran', banje dwoeji anheun gyeongu (반제되지 않은 경우) yang berarti bahwa 'ada tagihan pembayaran yang belum dibayarkan pembeli', pyojun wonga (표준 원가) yang berarti 'nilai harga dasar setelah semua biaya produksi dan biaya lain-lain ditambahkan' dan jajae kode jaego (자재 코드 재고) yang berarti 'stok kode dari material'. Selain kosakata yang sudah disebutkan, masih terdapat kosakata banpum banip cheori (반품 반입 처리) yang berarti 'pengelolaan retur yang masuk', 
yeongeob odeo (영업 오더) yang berarti 'order dari marketing', dan jumun odeo (주문 오더) yang berarti 'pemesanan dari pelanggan'.

Dari kosakata khusus yang muncul dalam surel bisnis berbahasa Korea, kosakata yang muncul berasal dari hanja. Kosakata ini susah digunakan jika tidak familiar atau tidak memahami konteks pengiriman surel. Utamanya kosakata pabrik, karena kosa kata yang digunakan sudah ditentukan dan disepakati.

Berbeda dengan kosakata khusus yang banyak muncul di pabrik manufaktur, ekspresi khusus tidak banyak ditemukan. Ini terjadi karena surel yang dikirimkan di pabrik manufaktur biasanya singkat. Setelah dianalisis, ada beberapa ekspresi yang digunakan khusus dalam surel bisnis Korea.

Tabel 8. Ekspresi Khusus dalam Surel Bisnis

\begin{tabular}{cc}
\hline Ekspresi yang digunakan & Jumlah \\
\hline Downgrader & 6 \\
Permohonan & 2 \\
Pengharapan & 3 \\
menyatakan tujuan & 2 \\
\hline
\end{tabular}

Sumber data: data penelitian

Dari tabel 8 dapat dilihat bahwa ada empat macam ekspresi yang biasa digunakan dalam surel bisnis. Downgrader atau dalam bahasa Korea disebut wanhwa pyohyeon (완화 표현) merupakan ekspresi pengurangan imbas dari tindakan yang tidak menyenangkan atau yang disebut oleh Brown dan Levinson (1987) disebagai face threatening act. Menurut Rosyadi (2019), downgrader dalam bahasa Indonesia dan bahasa Korea memiliki perbedaan sehingga menyulitkan pembelajar bahasa Korea. Ini disebabkan karena dalam kedua bahasa tersebut terdapat perbedaan ekspresi untuk mengurangi kekuatan dari tindakan ilukosioner dari ucapan dalam situasi yang tidak menyenangkan.

Tindakan ilukosiner adalah tindakan yang dilakukan karena ada maksud dan tujuan yang dikehendaki pembicara (Searle, 1979). Misalnya, seseorang mengatakan "keringatku bercucuran". Pembicara tidak hanya mengatakan bahwa keringatnya bercucuran. Di balik ucapan itu ada permintaan tidak langsung untuk membuka jendela atau menyalakan kipas angin. Untuk mengurangi pemaksaan dari tindakan tersebut, diperlukan ekspresi downgrader. Karena bahasa Korea kaya dengan akhiran atau biasa disebut eomi (어미), ekspresi downgrader tersebut banyak ditemukan di akhiran dalam bahasa Korea. Dalam pembagian tipe downgrader, akhiran termasuk dalam downgrader jenis tata bahasa (grammatical downgrader).

Downgrader yang muncul dalam surel bisnis digunakan agar penerima surel tidak merasa dipaksa atau disuruh ketika membaca surel tersebut. Berikut beberapa ungkapan downgrader dalam surel bisnis berbahasa Korea yang dianalisis.

e. $\mathrm{OO}$ 좋을 것 같습니다. OO joheul got gatsseumnida 'Akan lebih baik jika Anda....'

f. $\mathrm{OO}$ 주시면 되겠습니다 OO jusimyeon dwoegesseumnida 'Anda boleh me....' 
g. 여러므로 어려운 점이 많으 실텐데

Yeoreomero eoryeoun jeomi manheusiltende

'Banyak hal membuat sulit...'

$\mathrm{h}$. 언제 괜찮으신가요?

Eonje gwaenchaneusingayo?

'Kapan ada waktu?'

Kalimat e digunakan ketika pengirim ingin memberikan opininya terhadap suatu bahasan. Pola tata bahasa -eul got gattta (-(으)르 것 같다) digunakan untuk memberi kesan pendapat yang disampaikan itu lebih berupa saran. Kalimat f digunakan ketika pengirim ingin memberi tahu penerima bahwa beberapa hal boleh untuk dilakukan. Pola tata bahasa -myeon $d w o e d a$ (-면 되다) digabungkan dengan -get (-겠) agar penerima tidak merasa disuruh. Jika pengirim menulis "jakseonghae juseyo" (작성해 주세요) untuk meminta penerima surel membuat dokumen, di dalam bahasa Korea ekspresi tersebut masih terasa seperti menyuruh. Untuk menghindari bentuk suruhan tersebut, digunakanlah bentuk "jakseonghe jusimyeon dwoegesseumnida" (작성해 주시면 되겠습니다). Ekspresi ini berarti 'Anda boleh menyusun dokumen'. Kalimat g adalah bentuk ekspresi -eun/neunde (-(으)ㄴ/는데) yang digunakan untuk membuka kalimat agar terkesan tidak langsung menuju ke topik pembicaraan. Dalam bentuk pertanyaan seperti kalimat $h$, pengirim menggunaakan akhiran -eun-gayo? $(-($ 으) ᄂ가요?) untuk mengurangi daya tindakan ilokusioner. Pengirim bisa saja hanya menulis "eonje gwaenchanayo?"
(언제 괜찮아요?) untuk menanyakan 'kapan ada waktu?', tetapi ekspresi tersebut terlalu berterus terang (directive). Dalam bahasa Korea, untuk menanyakan kemauan lawan bicara, biasanya digunakan ekspresi -eulkkayo? (-(으)르 까요?) atau -eun/ neungayo? (-(으)ㄴ/는가요?) (Hwang, 2016).

Selain ekspresi downgrader, ada juga ekspresi untuk menunjukkan tujuan mengirim surel, ekspresi permohonan dan pengharapan. Ekspresi khusus untuk tujuan mengirim surel bisa ditulis seperti kalimat berikut "janghakssaengeul seonbalhagoja hamnida" (장학생을 선발하고자 합니다) yang artinya 'Kami ingin memilih penerima beasiswa'. Untuk surel yang berisikan formulir survei, biasanya ditulis "josareul chujinhago hamnida" (조사를 추진하고 합니다). Kalimat ini berarti 'Kami sedang melaksanakan survei'. Kata 'melaksanakan' dalam bahasa Korea memiliki banyak ekpresi seperti jinhaenghada (진행하다) dan silsihada (실시하다). Ekspresi permohonan bisa ditulis dengan menambahkan kata butakdeurida ('permohonan') di belakang kata yang diinginkan misalnya untuk mengungkapkan pernyataan 'Mohon kerjasama Anda' dalam bahasa Korea ditulis "Hyeopjjo butakdeurimnida" (협조 부탁드립니다). Hyeopjjo berarti 'kerja sama'. Kemudian untuk ekspresi pengharapan yang muncul di surel, salah satunya adalah "Hwoesineul bonae jusigi baramnida" (회신을 보내 주시기 바랍니다) yang arti harfiahnya 'Kami mengharapkan Anda mengirimkan balasan'. 


\section{3) Karakteristik Budaya dalam Surel}

\section{Bisnis Berbahasa Korea}

Budaya yang terlihat dalam surel bisnis Korea adalah budaya kesopanan. Bahasa Korea memiliki tingkatan kesopanan. Hanani (2018) mengemukakan bahwa bahasa Korea memiliki tingkat kesopanan untuk pelaku (subyek), objek dan pendengar sedangkan bahasa Indonesia hanya memiliki tingkat kesopanan untuk subyek dan pendengar. Tingkat kesopanan untuk obyek berpengaruh pada penulisan surel bisnis. Di dalam surel berbahasa Korea, terdapat penggunaan tingkat kesopanan untuk obyek seperti ege (에게) dan kke (께) yang berarti 'untuk', juda (주다) dan deurida (드리다) yang berarti 'memberikan', boda (보다) dan boeptta (뵙다) yang berarti 'bertemu'. Ege, juda dan boda tidak digunakan ketika mengirim surel kepada atasan atau penerima yang tidak dikenal dekat. Agar terlihat sopan, pengirim menggunakan kke, deurida, dan boeptta.

Karakteristik yang lain adalah adanya perbedaaan penulisan surel berdasarkan budaya kerja di masing-masing badan usaha. Surel yang dikirimkan ke seluruh pengajar di lembaga pendidikan, ditulis dengan bahasa yang sopan dan formal. Ini dapat dilihat dari penggunaan downgrader dan partikel honorifik -si (-시) Sedangkan surel yang dikirimkan oleh atasan, mempunyai bahasa lebih santai tetapi tetap formal. Berbeda dari surel yang diterima di perusahaan, surel di perusahaan biasanya lebih singkat dan padat. Namun, walaupun kenal dekat dan pengirim merupakan atasan penerima surel, pengirim tidak menggunakan bahasa pergaulan yang disebut banmal (반말) dalam bahasa Korea.

Selain kesopansantunan bahasa, di dalam surel juga biasanya terlihat jelas hierarki antara atasan dan bawahan. Hal itu disebabkan karena hirarki jabatan di perusahaan sangatlah banyak. Jika di Indonesia dengan mudah bisa disebut Pak atau $\mathrm{Bu}$, di Korea sebutan tersebut tidak lazim. Biasanya mereka akan menggunakan hoching atau sapaan ketika menulis surel. Di pembahasan sebelumnya ditemukan bahwa ada pengirim yang hanya menuliskan posisi pekerjaan saja. Contohnya damdangja (담당자) yang artinya 'penanggung jawab'.

\section{KESIMPULAN}

Karakteristik struktural, bahasa dan budaya dalam surel berbahasa Korea telah dianalisis. Dari hasil analisis tersebut ada beberapa hal yang bisa ditarik kesimpulan. Pertama, pembelajar bahasa Korea saat menulis surel bisnis bahasa Korea harus memperhatikan struktur surel baik judul, salam pembuka, bagian penutup dan salam penutup. Pembelajar tidak bisa hanya menulis surel berdasarkan struktur surel berbahasa Indonesia. Kedua, ekspresi dan kosakata yang muncul di surel bisnis sangatlah variatif, tetapi ada beberapa kosakata khusus dan ekspresi yang dapat digunakan sesuai dengan tujuan pengiriman surel. Ketiga, budaya kerja di Indonesia berbeda sehingga hal tersebut tercermin dalam surel yang dikirimkan. Perbedaan budaya ini haruslah dipahami agar 
kesalahpahaman yang disebabkan karena perbedaan budaya dapat dihindari saat berkomunikasi melalui surel. Keempat, setiap perusahaan dan badan usaha memiliki karakteristik yang berbeda dalam menuliskan surel. Pada penelitian ini, surel bisnis dari lembaga pendidikan dan surel bisnis dari perusahaan manufaktur memiliki karakteristik bahasa yang tidak sama karena keduanya bergerak di bidang yang berbeda.

\section{DAFTAR PUSTAKA}

Adobe. (2019). Email Usage - Working Age Knowledge Workers (US Trended Results).

https://www.slideshare.net/adobe/2019adobe-email-usage-study

Brown, P., \& Levinson, S. (1987). Politeness: Some Universals in Language Usage. Cambridge University Press.

Damar, W. A. (2010). Cerdas Ber-e-mail: Memaksimalkan Fungsi Surel untuk Komunikasi Online yang Efektif. Gagas Media.

Hanani, I. (2018). Error analysis on Korean honorific usage madeby Indonesian learners. Hankuk University of Foreign Studies.

Hwang, S. (2016). A Study on Indirect Speech Act of Korean learners through Analysis of Morphosyntactic Mitigation. The Korean Society of Bilingualism, 62, 185-208.

https://doi.org/10.17296/korbil.2016..62 .185
Kallos, J. (2008). Business E-mail Etiquette: The Manual. Lulu Press, Inc. Kim, A. (2012). Trading related E-mail Discourse Analysis for Korean Teaching. Korea University.

Kim, J. (2018). E-mail Text Analysis for Business E-mail Writing Techniques Teaching. Korea University.

Lee, Y. (2015). Developing educational materials for Korean for business purposes through email discourse analysis. The Society of Chung-Ang Language \& Literature, 61, 539-561. https://doi.org/10.15565/j11.2015.03.61.5 $\underline{39}$

Linyan, M. (2020). A Study on the Request Strategy Based on the Situation of Business Email. Seoul National University.

Myeong, D. S. (2019). Work Ethic in Company for Dummies. Fandombooks.

Rosyadi, A. A. (2019). A Study on the Use of Downgraders by Indonesian Intermediate Learners of Korean Language. Ewha Womans University.

Searle. (1979). Expression and meaning. Cambridge University Press.

Smith, L. A. (2002). Business E-mail: How to Make it Professional and Effective. Writing and Editing.

Xin, L. (2018). Korean Business E-mail Communication Educational Content Research: Mainly with Linguistic and Cultural Differences among Korea and China. Ewha Womans University. 